\title{
Management of the temporal muscle during cranioplasty: technical note
}

\author{
Stephen Honeybul, FRCS(SN), FRACS \\ Department of Neurosurgery, Sir Charles Gairdner Hospital, Nedlands; and Royal Perth Hospital, Perth, Western Australia, \\ Australia
}

Over the past 2 decades there has been a resurgence of interest in the use of decompressive craniectomy in the management of neurological emergencies. While technically straightforward, the procedure is associated with a number of complications relating to the initial decompression and subsequent cranioplasty. One complication that has received relatively little attention relates to the management of the temporal muscle. Here, through an illustrative case, the author describes a novel method of minimizing dissection of the temporal muscle during a cranioplasty procedure. Rather than placing a synthetic material over the dura mater to prevent adhesions or dissecting the muscle off the dura, the dura was opened and reflected laterally, pedicled to the temporal muscle. The dural defect was closed with a dural substitute, and the bone flap was secured in a routine fashion. The temporal muscle was then secured in its anatomical position. At the 6-month follow-up, radiological and clinical examination confirmed the restoration of muscle volume with excellent cosmetic and functional results. Opening the dura on a temporal muscle pedicle does not represent a routine form of surgical reconstruction; however, the use of this technique may have some advantages especially in young patients who have made a good recovery and for whom facial aesthetics may be particularly important.

http://thejns.org/doi/abs/10.3171/2015.11.PEDS15556

KEY WORDS decompressive craniectomy; cranioplasty; temporal muscle; craniofacial

$\mathrm{O}$ VER the past 2 decades there has been a global resurgence of interest in the use of decompressive craniectomy in the management of neurological emergencies. ${ }^{8}$ The procedure itself is technically straightforward, and there can be little doubt that it represents a life-saving intervention in the context of intractable intracranial hypertension. However, evidence that the procedure's outcome is better than that in patients who can survive following medical management is less forthcoming. ${ }^{3}$ This may be so for a number of reasons, not least of which is the morbidity associated with not only the initial decompressive surgery but also the subsequent cranioplasty., ${ }^{, 7,21}$

One issue that has received relatively little attention relates to the management of the temporal muscle, which is problematic for a number of reasons (Fig. 1). ${ }^{1}$ First, the muscle often becomes damaged when it is detached from the temporal bone during the initial craniectomy procedure. ${ }^{4}$ The dissection is often performed using monopolar coagulation to minimize blood loss; however, this coagulation can damage not only the vascular supply from the anterior and posterior deep temporal arteries, but also innervation from the masseteric and middle temporal nerves. This dissection can lead to loss of muscle bulk due to a combination of fiber retraction and atrophy. After the decompressive procedure, the muscle is often left lying over the exposed dura (Fig. 2) and, in cases in which a duraplasty has been performed, the dura substitute. Leaving the muscle in this condition often leads to further scarring and muscle retraction, and during the subsequent cranioplasty, the absence of a clear dissection plane often leads to a considerable amount of raw muscle exposure. Dissecting the muscle can increase the risk of postoperative hematoma formation, which is a relatively common complication following cranioplasty. ${ }^{2,5,18}$ Finally, there are functional and aesthetic problems that relate to muscle loss leading to masticatory difficulties and an unsatisfactory appearance due to temporal hollowing (Fig. 3). ${ }^{4}$

In an attempt to address these issues, a number of studies have described methods by which some of these complications can be minimized. In general, they revolve around a common theme in which some sort of synthetic barrier is placed between the dura (and duraplasty) and the temporalis muscle at the time of closure, following the initial decompressive procedure (Fig. 4). Examples of these synthetic barriers include silicone, silicon elastomer, bovine pericardium, polytetrafluoroethylene, and Seprafilm. .,4,6,9-20,22 $^{2}$

The following case features an alternative approach to this problem. 


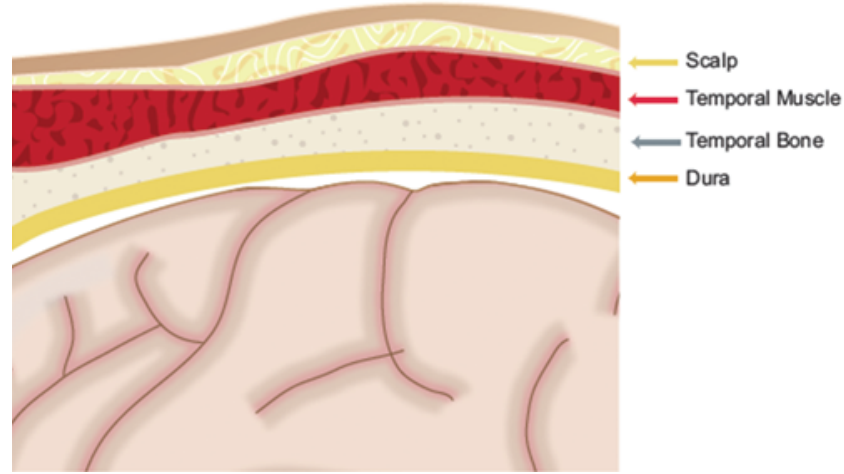

FIG. 1. Schematic representation of normal skull anatomy: skin and galea overlying temporal muscle, bone, dura, and cerebral cortex.

\section{Illustrative Case}

\section{History and Examination}

An 18-year-old man presented for an elective left-sided autologous cranioplasty procedure. Two months earlier, he had undergone decompressive craniectomy following evacuation of an acute subdural hematoma. He had allegedly been assaulted and sustained a single punch to the side of his head. On admission to the hospital and prior to intubation, clinical examination confirmed a Glasgow Coma Scale score of E2, M5, V2. Shortly after intubation and ventilation, his left pupil became fixed and dilated. Computed tomography scanning confirmed a large, leftsided, acute subdural hematoma with an approximately 5 -mm midline shift. He was immediately taken to the operating theater. At the time of surgery, the subdural hematoma was evacuated uneventfully; however, the brain was found to be edematous such that replacement of the bone flap was thought to be problematic. An extensive duraplasty was performed using locally harvested pericranium, and the bone flap was preserved in a refrigerated sterile container. After a 6-day stay in the intensive care unit, the patient was transferred initially to the ward and then to a rehabilitation facility. He went on to make a good recovery, and prior to the cranioplasty he was well and had no focal neurological deficits.

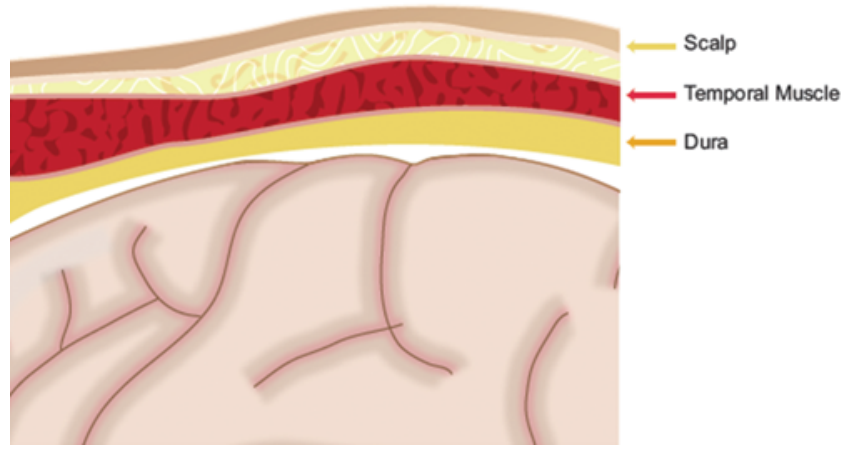

FIG. 2. Following decompressive craniectomy, the temporalis muscle becomes adherent to the underlying dura.

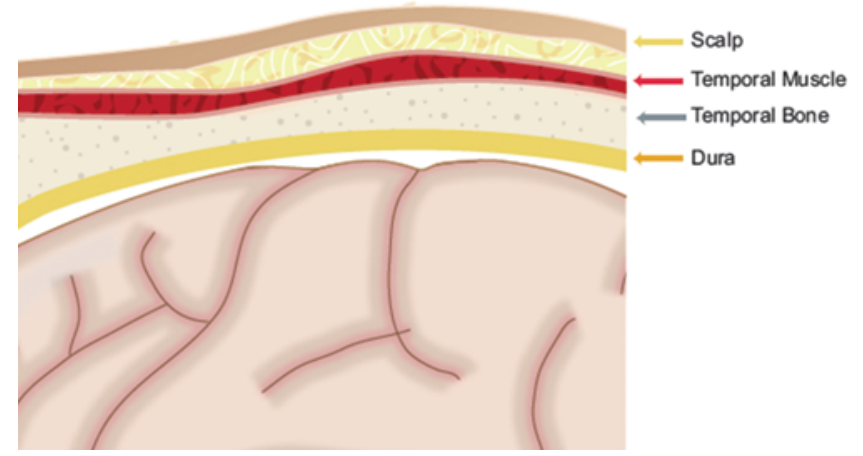

FIG. 3. During the cranioplasty procedure, further dissection of the temporal muscle leads to atrophy of the muscle and subsequent temporal hollowing.

\section{Operation}

He was readmitted to the neurosurgical facility for an autologous cranioplasty procedure. Following uneventful reflection of the scalp flap, the temporal muscle was found to be densely adherent to the dura, and there was no clear plane of dissection. Several attempts were made to dissect the temporalis muscle off the dura, but they failed. An attempt was also made to leave the temporal muscle attached to the dura and to replace the bone flap over both structures; however, the bulk of the temporal muscle made this problematic despite the use of mannitol to relax the brain.

A number of areas where the previous duraplasty had failed were noticed, and the cortical surface of the brain was clearly visible. It was then decided that the simplest thing to do would be to open the dura circumferentially, leaving the inferior aspect pedicled on the temporal muscle. The dural defect was reconstructed using DuraGen (Integra LifeSciences Corp.), a synthetic dura substitute. The bone was replaced and secured with miniplates, and the temporal muscle was replaced in its anatomical position and secured by suturing the dural edges to the underside of the galea around the scalp flap incision by using a synthetic absorbable sterile surgical suture (Fig. 5).

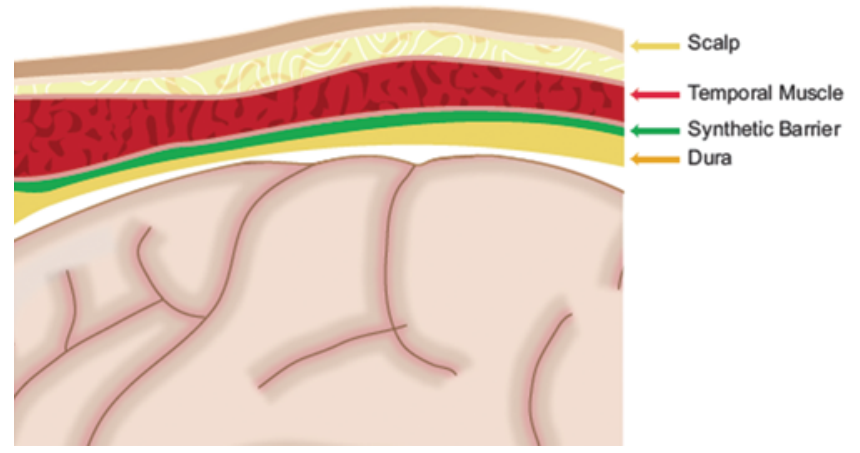

FIG. 4. To prevent adhesions between the temporal muscle and the dura, a synthetic material (green) can be placed over the dura, deep to the temporal muscle, at the time of closure, following the initial surgical decompression. 


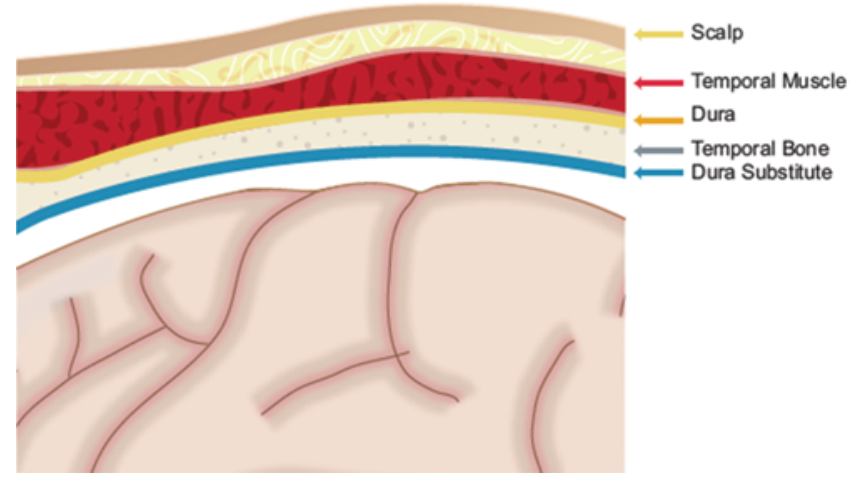

FIG. 5. An alternative approach is to open the dura and leave it on a temporal muscle pedicle. The dural defect can be repaired with a proprietary dural substitute (blue).

\section{Postoperative Course}

The patient went on to make an uneventful recovery with no evidence of postoperative CSF leakage, and at the 6-month follow-up the cosmetic and functional results were excellent (Fig. 6).

\section{Discussion}

When considering the potential life-saving nature of a decompressive craniectomy in the context of neurological emergencies, management of the temporal muscle in terms of functional and aesthetic outcome would appear to be of relatively minor importance. However, given that both the initial decompressive surgery and the subsequent cranioplasty procedure are now known to be associated with significant morbidity, it may be reasonable to make as much effort as possible to minimize any potentially deleterious effects of surgery.

A number of methods that aim to place some sort of synthetic barrier between the temporal muscle and the dura at the time of the initial decompressive surgery have been described. ${ }^{2,4,6,9-20,22}$ All of these methods would appear reasonable; however, they are not always possible, and in many cases the temporal muscle becomes firmly adherent to the dura especially when pericranial duraplas-
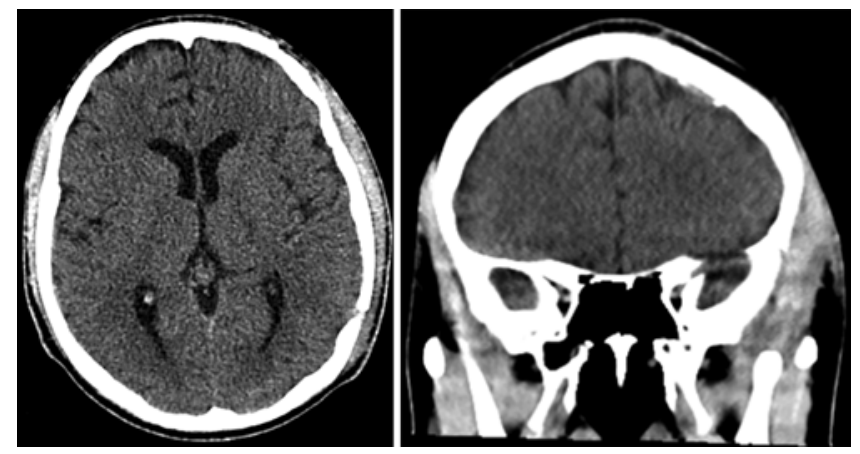

FIG. 6. Axial (left) and coronal (right) CT images obtained 6 months following left-sided autologous cranioplasty, showing excellent restoration of temporalis muscle bulk. ty has been performed. It is by no means suggested that opening the dura on a temporal muscle pedicle represents a routine form of surgical reconstruction. However, dural resection and reconstruction are common undertakings in many neurosurgical procedures such as meningioma resection, and the management of cortical adhesions and cerebral swelling is part of any neurosurgeon's armamentarium

While neurosurgeons are adept at dealing with dural adhesions to the brain, there are some situations in which this technique may be contraindicated, such as when there are defects in the dural repair that have led to direct musculo-leptomeningeal cicatrization. However, if there is a clean plane of dissection, the use of this technique may have some advantages especially in young patients who have made a good recovery and for whom facial aesthetics may be particularly important.

A number of limitations require consideration. It remains to be established whether the lack of temporal muscle dissection reduces the incidence of postoperative hematoma; however, the preservation of muscle mass and an excellent aesthetic result may represent a good enough reason to consider the use of this technical variation in certain circumstances. In addition, a larger series of patients must be followed up to confirm that less dissection of the temporal muscle does indeed lead to improved cosmetic and masticatory function. Finally, a larger series is required to establish that any provided benefits are not outweighed by potential complications such as CSF leak, seizures, subdural hematoma, or focal deficit due to either direct cortical injury or devascularization.

\section{Acknowledgments}

I thank Ms. Nita Dening, medical illustrator, Audiovisual Production Unit, Sir Charles Gairdner Hospital, for the illustrations in Figs. 1-5.

\section{References}

1. Adeleye AO, Azeez AL: Decompressive craniectomy bone flap hinged on the temporalis muscle: a new inexpensive use for an old neurosurgical technique. Surg Neurol Int 2:150, 2011

2. Bulters D, Belli A: Placement of silicone sheeting at decompressive craniectomy to prevent adhesions at cranioplasty. $\mathbf{B r}$ J Neurosurg 24:75-76, 2010

3. Cooper DJ, Rosenfeld JV, Murray L, Arabi YM, Davies AR, D'Urso P, et al: Decompressive craniectomy in diffuse traumatic brain injury. N Engl J Med 364:1493-1502, 2011

4. Di Rienzo A, Iacoangeli M, Alvaro L, Colasanti R, Nocchi N, Di Somma LG, et al: Autologous vascularized dural wrapping for temporalis muscle preservation and reconstruction after decompressive craniectomy: report of twenty-five cases. Neurol Med Chir (Tokyo) 53:590-595, 2013

5. Gooch MR, Gin GE, Kenning TJ, German JW: Complications of cranioplasty following decompressive craniectomy: analysis of 62 cases. Neurosurg Focus 26(6):E9, 2009

6. Gordon CR, Fisher M, Liauw J, Lina I, Puvanesarajah V, Susarla S, et al: Multidisciplinary approach for improved outcomes in secondary cranial reconstruction: introducing the pericranial-onlay cranioplasty technique. Neurosurgery 10 (Suppl 2):179-190, 2014

7. Honeybul S: Complications of decompressive craniectomy for head injury. J Clin Neurosci 17:430-435, 2010 
8. Honeybul S, Ho KM: The current role of decompressive craniectomy in the management of neurological emergencies. Brain Inj 27:979-991, 2013

9. Huang YH, Lee TC, Chen WF, Wang YM: Safety of the nonabsorbable dural substitute in decompressive craniectomy for severe traumatic brain injury. J Trauma 71:533-537, 2011

10. Kawaguchi T, Hosoda K, Shibata Y, Koyama J: Expanded polytetrafluoroethylene membrane for prevention of adhesions in patients undergoing external decompression and subsequent cranioplasty. Neurol Med Chir (Tokyo) 43:320 324,2003

11. Lee CH, Cho DS, Jin SC, Kim SH, Park DB: Usefulness of silicone elastomer sheet as another option of adhesion preventive material during craniectomies. Clin Neurol Neurosurg 109:667-671, 2007

12. Malliti M, Page P, Gury C, Chomette E, Nataf F, Roux FX: Comparison of deep wound infection rates using a synthetic dural substitute (neuro-patch) or pericranium graft for dural closure: a clinical review of 1 year. Neurosurgery 54:599_ 604, 2004

13. Missori P, Paolini S, Ciappetta P, Seferi A, Domenicucci M: Preservation of the temporal muscle during the frontotemporoparietal approach for decompressive craniectomy: technical note. Acta Neurochir (Wien) 155:1335-1339, 2013

14. Missori P, Polli FM, Peschillo S, D’Avella E, Paolini S, Miscusi M: Double dural patch in decompressive craniectomy to preserve the temporal muscle: technical note. Surg Neurol 70:437-439, 2008

15. Miyake S, Fujita A, Aihara H, Kohmura E: New technique for decompressive duraplasty using expanded polytetrafluoroethylene dura substitute-technical note. Neurol Med Chir (Tokyo) 46:104-106, 2006

16. Mumert ML, Altay T, Couldwell WT: Technique for decompressive craniectomy using Seprafilm as a dural substitute and anti-adhesion barrier. J Clin Neurosci 19:455-457, 2012
17. Nakagawa S, Hayashi T, Anegawa S, Nakashima S, Shimokawa S, Furukawa Y: Postoperative infection after duraplasty with expanded polytetrafluoroethylene sheet. Neurol Med Chir (Tokyo) 43:120-124, 2003

18. Oladunjoye AO, Schrot RJ, Zwienenberg-Lee M, Muizelaar JP, Shahlaie K: Decompressive craniectomy using gelatin film and future bone flap replacement. J Neurosurg 118:776-782, 2013

19. Sharma SD, Lim B, Bentley RP: Preservation of the temporalis muscle during cranioplasty. Br J Oral Maxillofac Surg 50:e36-e37, 2012

20. Vakis A, Koutentakis D, Karabetsos D, Kalostos G: Use of polytetrafluoroethylene dural substitute as adhesion preventive material during craniectomies. Clin Neurol Neurosurg 108:798-802, 2006

21. Yang XF, Wen L, Shen F, Li G, Lou R, Liu WG, et al: Surgical complications secondary to decompressive craniectomy in patients with a head injury: a series of 108 consecutive cases. Acta Neurochir (Wien) 150:1241-1248, 2008

22. Zhang GL, Yang WZ, Jiang YW, Zeng T: Extensive duraplasty with autologous graft in decompressive craniectomy and subsequent early cranioplasty for severe head trauma. Chin J Traumatol 13:259-264, 2010

\section{Disclosures}

The author reports no conflict of interest concerning the materials or methods used in this study or the findings specified in this paper.

\section{Correspondence}

Stephen Honeybul, Department of Neurosurgery, 5th Fl., North Block, Royal Perth Hospital, Wellington St., Perth, WA 6000, Australia.email: stephen.honeybul@health.wa.gov.au. 